\title{
Multimodality imaging of anomalous pulmonary veins
}

\author{
Roman Nepomuceno ${ }^{1}$, Matthew Zeglinski ${ }^{1}$, Jordyn Lerner' ${ }^{1}$, Wlodzimierz Czarnecki ${ }^{2}$, lain DC Kirkpatrick ${ }^{3}$, \\ Jacek Strzelczyk ${ }^{3}$, Davinder S Jassal ${ }^{1,2,3^{*}}$
}

\begin{abstract}
Partial anomalous pulmonary venous connection (PAPVC) is an extremely rare congenital condition where one or more of the pulmonary veins are connected to the venous circulation. Although initially suspected with unexplained right ventricular enlargement on transthoracic echocardiography (TTE), cardiac MRI is able to delineate the anatomical variant. We present a case of a 65-year-old male diagnosed with left sided PAPVC using multimodality cardiac imaging.
\end{abstract}

\section{Case Report}

A 65-year-old male with diabetes, hyperlipidemia, and hypertension presented with palpitations in the absence of dyspnea, chest pain, nor syncope. On physical examination, the patient was hypertensive with a blood pressure of $167 / 125 \mathrm{mmHg}$. The jugular venous pressure (JVP) and carotid contour were normal. There was evidence of a parasternal lift, consistent with right ventricular (RV) enlargement with no evidence of cardiac murmurs. Transthoracic echocardiography (TTE) confirmed moderate RV enlargement with preserved systolic function. A small patent foramen ovale (PFO) was identified with left-to-right shunting on color Doppler (Figure 1A and 1B, Additional File 1, Movie 1A and Additional File 2, Movie 1B). Transesophageal echocardiography (TEE) confirmed the left-to-right shunt across the PFO by color Doppler with intermittent right-to-left flow following administration of agitated saline contrast (Figure 1C, Additional File 3, Movie 1C). However, the degree of RV enlargement on both TTE and TEE was disproportionate to the interatrial shunt. Cardiac magnetic resonance imaging (CMR) demonstrated a congenital partial anomalous connection of both left pulmonary veins to the innominate vein as the etiology of RV enlargement (Figure 1D).

\footnotetext{
* Correspondence: djassal@sbgh.mb.ca

${ }^{1}$ Institute of Cardiovascular Sciences, St. Boniface Research Centre, University of Manitoba, Winnipeg, Manitoba, Canada

Full list of author information is available at the end of the article
}

\section{Discussion}

Partial anomalous pulmonary venous connection (PAPVC) is an extremely rare congenital condition where one or more of the pulmonary veins are connected to the venous circulation. Its prevalence within the general population is $0.4-0.7 \%$ [1]. Approximately $90 \%$ of all PAPVC's originate from the right lung, $7 \%$ originate from the left lung, and $3 \%$ of patients are found to have bilateral PAPVC's originating from both lungs connecting to either the superior vena cava (SVC), the inferior vena cava (IVC), the right atrium or the innominate vein [2]. Common congenital cardiac conditions associated with PAPVC include sinus venosum and ASD secundum defects [1-4]. Clinical presentation of PAPVC may include dyspnea, chest pain, fatigue, syncope, and/or a decreased exercise tolerance [1-4]. On physical examination, individuals with PAPVC may present with an elevated JVP, parasternal lift due to RV enlargement, a right sided S3 and pulmonary hypertension [1-4].

Echocardiography is the initial modality of choice for the noninvasive detection of PAPVC $[1,5]$. Transthoracic echocardiography (TTE) identifies right atrial and RV enlargement, flattening of the interventricular septum in systole and diastole due to RV pressure overload, elevated pulmonary pressures [6], and/or the presence of an interatrial shunt on color Doppler. In addition to PAPVC, other cardiac entities to consider in the differential diagnosis of unexplained RV enlargement on echocardiography include sinus venosus defect, ostium primum or ASD secundum, or arrythmogenic right 


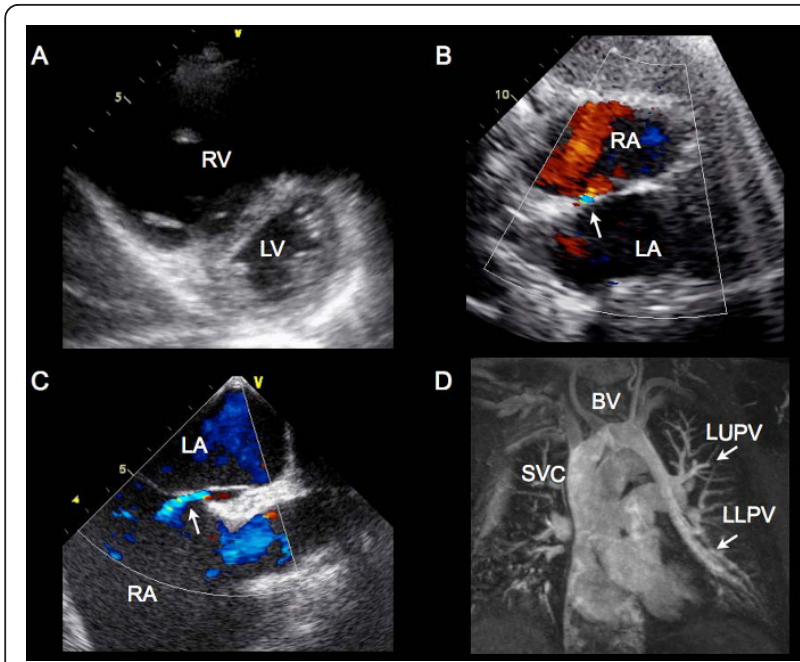

Figure 1 Multimodality imaging of anomalous pulmonary veins: A) A parasternal short axis view on TTE demonstrating moderate RV enlargement. RV, right ventricle; LV, left ventricle. B) A subxiphoid view on TTE demonstrating left to right shunting across the interatrial septum on color Doppler, consistent with a PFO. RA, right atrium; LA, left atrium. C) A midesophageal view on TEE demonstrating left to right shunting across the interatrial septum on color Doppler, consistent with a PFO. RA, right atrium; LA, left atrium. D) Cardiac magnetic resonance imaging (CMR) demonstrated a congenital partial anomalous connection of both left pulmonary veins to the innominate vein. SVC, superior vena cava; BV, brachiocephalic vein; LUPV, left upper pulmonary vein; LLPV, left lower pulmonary vein.

ventricular dysplasia. Although TTE is unable to characterize the anatomy of the pulmonary veins, TEE is able to confirm the presence or absence of a PAPVC [1]. If all four pulmonary veins are not identified emptying into the LA on TEE [1], CMR may provide complementary information $[7,8]$. Due to the higher spatial resolution and increased field of view of CMR, the presence or absence of a PAPVC and quantification of a shunt can be easily identified $[7,8]$.

Individuals with a Qp/Qs shunt ratio higher than 1.5:1 with RV enlargement should undergo surgical correction of the PAPVC [9]. A pulmonary vein can be connected through a baffle or directly back to the left atrium, with surgical correction of a concomitant ASD with a patch if required [9]. In patients with PAPVC, the right atrium may require a larger prosthetic or pericardial patch for repair than an isolated ASD repair, which may cause complications including sick sinus syndrome, variable AV block or obstruction of the superior vena cava [9]. In our case, the patient was asymptomatic with a Qp/Qs of 1.1:1 on CMR, and hence followed conservatively on an annual basis.

\section{Conclusion}

In a patient with unexplained RV enlargement disproportionate to the presence of a small PFO, PAPVC should be considered in the differential diagnosis. Multimodality cardiac imaging using echocardiography and CMR may provide a comprehensive noninvasive evaluation of PAPVC.

\section{Consent}

Written informed consent was obtained from the patient for publication of this case report and accompanying images. A copy of the written consent is available for review by the Editor-in-Chief of this journal.

\section{Additional material}

Additional file 1: A parasternal short axis view on TTE demonstrating RV enlargement. Movie $1 \mathrm{~A}$.

Additional file 2: A subxiphoid view on TTE demonstrating a PFO with left to right shunting on color Doppler. Movie 1B.

Additional file 3: A midesophageal view on TEE demonstrating a PFO with left to right shunting on color Doppler. Movie $1 C$.

\section{Author details}

${ }^{1}$ Institute of Cardiovascular Sciences, St. Boniface Research Centre, University of Manitoba, Winnipeg, Manitoba, Canada. ${ }^{2}$ Section of Cardiology, Department of Internal Medicine, University of Manitoba, Winnipeg, Manitoba, Canada. ${ }^{3}$ Department of Radiology, University of Manitoba, Winnipeg, Manitoba, Canada.

\section{Authors' contributions}

$R N, M Z, J L, W C, J S, I K$, and DJ contributed to the writing of the manuscript. All authors read and approved the final manuscript.

\section{Competing interests}

The authors declare that they have no competing interests.

Received: 4 January 2011 Accepted: 2 February 2011

Published: 2 February 2011

\section{References}

1. Ammash NM, Seward JB, Warnes CA, Connolly HM, O'Leary PW, Danielson GK: Partial Anomalous Pulmonary Venous Connection: Diagnosis by Transesophageal Echocardiography. J Am Coll Cardiol 1997, 29:1351-8.

2. EIBardissi AW, Dearani JA, Suri RM, Danielson GK: Left-Sided Partial Anomalous Pulmonary Venous Connections. Ann Thorac Surg 2008, 85:1007-14.

3. Hijii T, Fukushige J, Hara T: Diagnosis and Management of Partial Anomalous Pulmonary Venous Connection. Cardiology 1998, 89:148-151.

4. AboulHosn JA, Criley JM, Stringer WW: Partial Anomalous Pulmonary Venous Return: Case Report and Review of the Literature. Catheterization and Cardiovascular Interventions 2003, 58:548-552.

5. Hausmann D, Daniel WG, Mugge A, Ziemer G, Pearlman AS: Value of transesophageal color Doppler echocardiography for detection of different types of atrial septal defects in adults. J Am Soc Echocardiogr 1992, 5:481-8.

6. Roule V, Labombarda F, Pellissier A, Sabatier R, Lognone T, Gomes S, Bergot E, Milliez P, Grollier G, Saloux E: Echocardiographic assessment of pulmonary vascular resistance in pulmonary arterial hypertension. Cardiovascular Ultrasound 2010, 8:21.

7. Prompona M, Muehling O, Naebauer M, Schoenberg SO, Reiser M, Huber A: MRI for Detection of Anomalous Pumonary Venous Drainage in Patients with Sinus Venosus Atrial Septal Defects. Int J Cardiovasc Imaging 2010.

8. Teo KSL, Disney PJ, Dundon BK, Worthley ML, Brown MA, Sander P, Worthley SG: Assessment of Atrial Septal Defects in Adults Comparing 
Cardiovascular Magnetic Resonance with Transoesophageal

Echocardiography. Journal of Cardiovascular Magnetic Resonance 2010,

12:44.

9. Alsoufi B, Cai S, Van Arsdell GS, Williams WG, Caldarone CA, Coles JG:

Outcomes After Surgical Treatment of Children with Partial Anomalous

Pulmonary Venous Connection. Ann Thorac Surg 2007, 84:2020-6.

doi:10.1186/1476-7120-9-3

Cite this article as: Nepomuceno et al: Multimodality imaging of

anomalous pulmonary veins. Cardiovascular Ultrasound 2011 9:3.

Submit your next manuscript to BioMed Central and take full advantage of:

- Convenient online submission

- Thorough peer review

- No space constraints or color figure charges

- Immediate publication on acceptance

- Inclusion in PubMed, CAS, Scopus and Google Scholar

- Research which is freely available for redistribution

Submit your manuscript at 